\title{
Climate Adaptation Planning in the Monterey Bay Region: An Iterative Spatial Framework for Engagement at the Local Level
}

\author{
Sarah M. Reiter ${ }^{1 *}$, Lisa M. Wedding ${ }^{1}$, Eric Hartge ${ }^{1}$, Letise LaFeir ${ }^{2}$, Margaret R. Caldwell ${ }^{1}$ \\ ${ }^{1}$ Center for Ocean Solutions, Monterey, CA, USA \\ ${ }^{2}$ Monterey Bay Aquarium, Monterey, CA, USA \\ Email: smmooney@stanford.edu
}

Received 24 April 2015; accepted 25 May 2015; published 28 May 2015

Copyright @ 2015 by authors and Scientific Research Publishing Inc.

This work is licensed under the Creative Commons Attribution International License (CC BY).

http://creativecommons.org/licenses/by/4.0/

\section{(c) (i) Open Access}

\begin{abstract}
The Monterey Bay Region benefits from science-based adaptation planning that places value on a healthy social-ecological ecosystem. We co-developed a methodological engagement framework to support an iterative place-based process among natural resource managers, the planning community, and the community of technical experts (e.g., economists, scientists, lawyers). In collaboration with local decision makers, we are evaluating the effects of adaptation strategies on ecosystem services provided by natural dune and wetland systems to inform decision making at the local government level. Here, we present the Center for Ocean Solutions' transferable engagement framework designed to evaluate viable climate adaptation planning alternatives using spatial analysis and data visualization techniques.
\end{abstract}

\section{Keywords}

Climate Change Adaptation, Wetlands Management, Coastal Restoration, Ecosystem Services

\section{Introduction}

The Monterey Bay Region along the Central coast of California is home to a diverse ocean-based economy that supports a suite of competing human uses (e.g., agriculture, cattle grazing, railroad and road construction, fishing, energy generation, marine research, tourism, recreation). At the heart of the region is Elkhorn Slough, an

*Corresponding author.

How to cite this paper: Reiter, S.M., Wedding, L.M., Hartge, E., LaFeir, L. and Caldwell, M.R. (2015) Climate Adaptation Planning in the Monterey Bay Region: An Iterative Spatial Framework for Engagement at the Local Level. Natural Resources, 6, 375-379. http://dx.doi.org/10.4236/nr.2015.65035 
estuarine system with a mosaic of mudflats, eelgrass beds and salt marshes that provide habitat for more than two dozen rare, threatened or endangered species [1]. As one of only a few remaining saltwater wetlands on the Pacific flyway (i.e., north-south flyway for migratory birds extending from Alaska to Patagonia), it is also a critical habitat for migratory bird species. Elkhorn Slough has engineered structures (e.g., levees, embankments, harbor) at the mouth of and throughout the estuary, which significantly influence the natural structure and function of the estuarine system [2]. A changing climate and its associated impacts (e.g., rising seas increased storm events) will serve as a risk multiplier, leaving this biogeographically significant estuarine system ecologically and socially vulnerable. In Monterey Bay, the impacts of future large El Niño Southern Oscillation (ENSO) events will be greater than those historic events of similar magnitude, exposing coastal areas to the combined effects of sea level rise, elevated sea levels from El Niño events, and large waves [3].

Knowledge gaps exist among natural, physical and social science research communities and policymakers whose decisions affect the health of estuarine ecosystems and coastal communities like Elkhorn Slough. These gaps present opportunities to better align research agendas with decision-making needs, enhance decision-making capacity to apply relevant research findings and engage in active learning that informs new decisions. Faced with complex environmental problems that have profound implications for the future, we urgently need new organizational mechanisms to more effectively link scientific understanding to natural resource management. Boundary organizations exist at the interface of research and policy organizations and foster linkages necessary to help fill such gaps.

As a boundary organization, the Center for Ocean Solutions works to support this coastal region's capacity to engage in long-term, science-based adaptation planning that places value on maintaining and enhancing a healthy social-ecological ecosystem. Specifically, the Center's first objective was to develop a viable and repeatable methodology to support an iterative place-based process between natural resource managers, the planning community, and the community of technical experts (e.g., economists, scientists, lawyers). In collaboration with local decision makers, the Center 1) evaluates the effects of adaptation strategies on ecosystem services provided by natural wetland systems, 2) informs decision making, and 3) enhances the capacity of municipalities. The Center's second objective was to implement a spatial approach to evaluate competing and overlapping human uses that co-occur with increased climate change vulnerability. Here, we present the Center's methodological framework and initial findings from the spatial adaptation planning process.

\section{Methods}

\subsection{Iterative Process for Engagement at the Local Level}

The Center for Ocean Solutions bridges the gap between the best available science, law and policy analytics, and coastal planning decisions. In the Monterey Bay Region, the Center's approach is to utilize the Iterative Process between technical experts and decision makers to produce boundary objects (i.e., models, scenarios, and assessment reports produced jointly by experts and decision makers) that ensure successful adaptation planning at a local level [4]. The Iterative Process—refined based on lessons learned from similar local-level engagements in California [5] — consists of working alongside decision makers in the study area to co-develop and tailor the Center's analytics through each phase of the Engagement Framework to ensure that the Center's research is applicable to decision-making needs. The Iterative Process is also designed to span each phase of the Engagement Framework in order to address the key attributes of a boundary organization's function: credible, legitimate, and salient information [4].

\subsection{Spatial Adaptation Planning}

In conjunction with the Iterative Process, the Monterey Bay Region needs a spatial framework to ensure successful adaptation planning at a local level. Spatial adaptation planning can provide a critical place-based context and set of tools to facilitate successful adaptation to climate change [6]. We applied spatial adaptation planning to address potential user conflicts in the Center's study area and initial findings highlight significant spatial overlap in human use and coastal vulnerability to sea level rise and associated flooding. Specifically, we used Geographic Information Systems (GIS) to integrate the patterns of coastal land use and critical transportation infrastructure demonstrating a future coastal community with increased vulnerability under a number of National Oceanic and Atmospheric Administration (NOAA) sea level rise scenarios for the Monterey Bay area. In addition, the predicted extent of coastal inundation and flooding from 1 foot to 6 feet above high tide were mapped 
using Federal Emergency Management Agency (FEMA) data. The maps initiated an iterative dialogue within a network of local planners, business owners, research institutes, and technical experts. This dialogue is aimed at better serving local communities in their adaptation planning efforts by both coordinating and utilizing the expertise of existing institutions.

\section{Preliminary Results in the Monterey Bay Region}

\subsection{Methodological Engagement Framework}

The Engagement Framework (Figure 1) utilizes the Iterative Process to support climate adaptation planning at the local level, and the Center's preliminary results suggest four essential phases. Due diligence, including acquisition of data and commencement of legal and scientific research, composes the first phase. The second phase entails engaging in dialogue with collaborators to verify the best inputs from the scientific, law and policy context. The third phase involves verifying the analysis and ensuring outputs are relevant for the decision-making context. The final step requires communication of results in a manner relevant to the decision-making context. The preliminary results also suggest that application of the Engagement Framework will produce place-based boundary objects that initiate dialogue regarding climate adaptation planning options, and are grounded in the best available science as well as law and policy analytics for the study area (Figure 2).

\subsection{Spatial Adaptation Planning}

As baseline sea level height continues to increase, the impacts of large storm events will also increase. The Center's preliminary results allowed decision makers to visualize the mapped extent of a 100-year coastal flood,

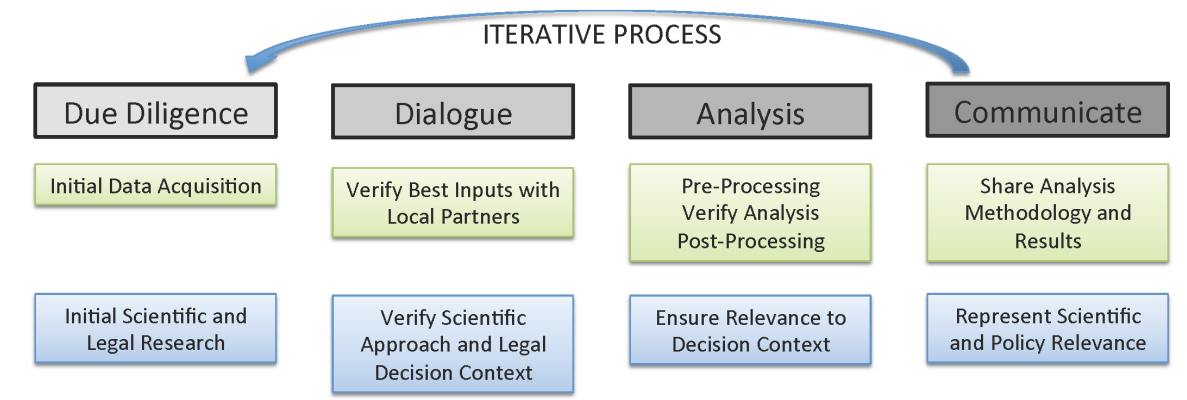

Figure 1. Iterative engagement process to support climate adaptation planning at the local-level.

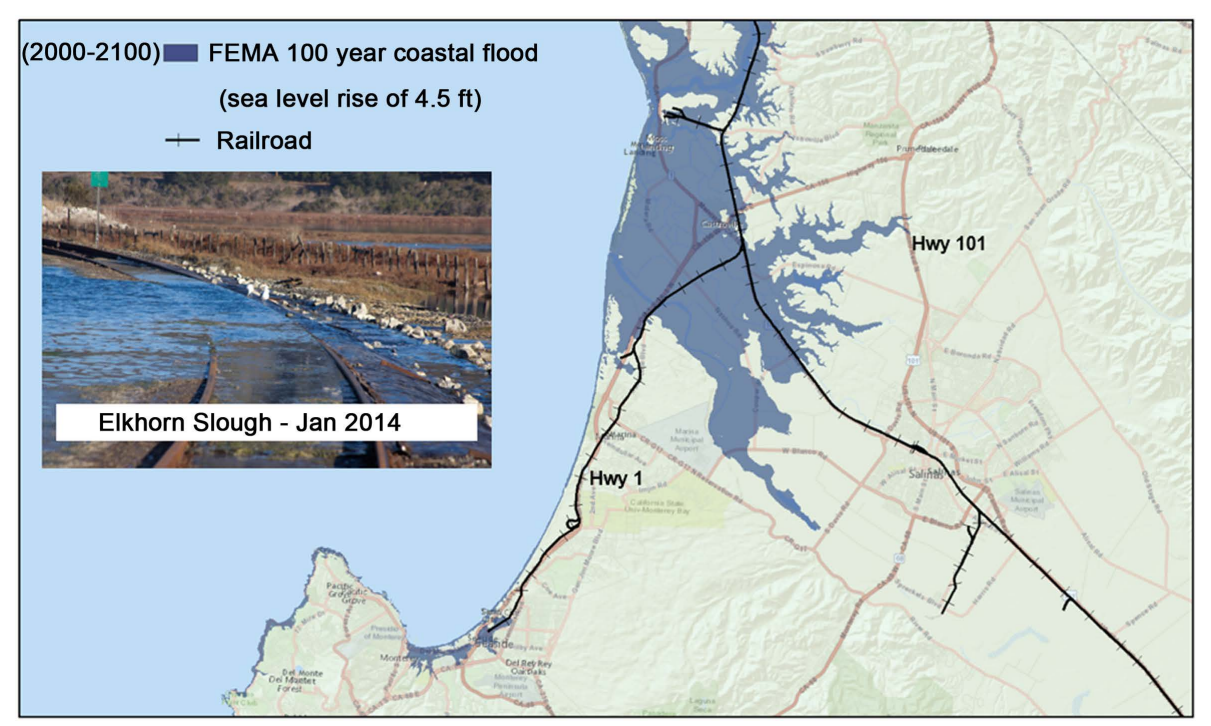

Figure 2. Transportation infrastructure in southern Monterey Bay with a 100 year coastal flood and $4.5 \mathrm{ft}$ sea level rise scenario. 
based on FEMA 100-year flood elevations, with a sea level rise of 4.5 feet as projected by year 2100 (Figure 2). In the Monterey Bay Region, sea level rise and flooding will play a role along this coast; the low elevation areas from Moss Landing Harbor to Marina were found to be most at risk when considering critical transportation infrastructure that connects these coastal communities with Highway 1. Through the Center's iterative engagements, we found that the City of Monterey also has high-priority vulnerability: the Union Pacific Railroad tracks that span Elkhorn Slough already experience flooding during King Tide events. This flooding coupled with the transport of oil has the potential to impact environmentally sensitive areas on which southern sea otters, other species and humans depend for habitat or other ecosystem services. As a result, the Center spatially mapped the issue by overlaying the rail infrastructure in order to visualize and communicate the resulting concerns (Figure 1).

The Center has utilized these preliminary results and map products during engagement meetings to 1) initiate a place-based dialogue with municipalities; 2) screen and visualize hotspots of potential conflict; and 3) facilitate discussions about adaptation planning options. Spatial planning in coastal communities at a local level serves a key role in promoting robust climate adaptation measures [6] [7]. Using the outcomes of the Center's spatial adaptation planning and Engagement Framework to evaluate the impacts from coastal flooding, local policymakers are considering two specific spatial adaptation planning options: 1) dune restoration at the mouth of Elkhorn Slough; and 2) managed retreat along Del Monte Beach.

\section{Discussion}

\subsection{Informing the Climate Adaptation Planning Process in the Monterey Bay Region}

The Center for Ocean Solutions is exploring how the Monterey Bay Region can adapt to a changing climate in a way that supports its vibrant coastal economies and abundant natural resources. Local jurisdictions are using the Center's spatial adaptation planning information to guide their adaptation planning and decision making. This process entails the selection of certain adaptation options and implementation of associated design strategies. There are several adaptation options that, to varying degrees, account for protecting both the built environment and coastal resources [8]. Within these options, grey and green design strategies are utilized by coastal planners. Grey design strategies are traditional approaches that generally do not take the role of coastal habitats into account [9]. Alternatively, green design strategies consist of nature-based approaches that account for the role of habitats in reducing exposure to climate change and associated impacts and in providing additional benefits beyond coastal protection, such as supporting wildlife, coastal tourism and/or property values [10].

\subsection{Operationalizing Adaptation Strategies for the Monterey Bay Region}

Historically, policymakers in the Monterey Bay Region have used a grey design strategy of coastal armoring. But coastal armoring is only a short-term solution, with high costs to coastal resources [11]. The Window on the Bay Project is an example of the Monterey Bay Region's shift away from this approach. Situated along Monterey's main traffic artery, the project involves managed retreat of the built environment away from the shoreline to account for local priorities (e.g., traffic safety, public access, tourism). The region is also exploring proactive use of dune habitat as a physical barrier between land and sea, with a study site at the mouth of Elkhorn Slough. Dune restoration aims to protect against storm surge and flooding, but also has the additional benefits of supporting wildlife and coastal tourism. These are two examples of current projects chosen by decision makers that are indicative of the several good options for climate adaptation planning. These options become operationalized and shovel ready through spatial adaptation planning. The Elkhorn Slough study area is ripe for exploration of hybrid approaches that incorporate both engineered and habitat-based designs.

\subsection{Scaling and Transferability}

Climate change and adaptation planning is a globally relevant issue in which the scalability of solutions should be considered. This work has outlined a framework for adaptation planning at local and regional scales. Next steps can address scalability of this work to the state, national and international levels. Beyond spatial scale, the temporal scale of adaptation planning is critical because of the mismatch between the long-term implications of climate change and short-term planning horizons. This temporal issue is not unique to California and is an important next step to address in climate adaptation planning for the Monterey Bay Region. 


\section{Acknowledgements}

We would like to thank Ashley L. Erickson, Rebecca G. Martone, and Molly L. Melius for their continued guidance, input and support. The Center's work for this project was made possible by the financial support of the David and Lucile Packard Foundation. Many thanks to the members of the Monterey Bay Region planning community for their continued dedication to preparing for a more resilient future.

\section{References}

[1] Caffrey, J., Brown, M., Tyler, W.B. and Silberstein, M. (Eds.) (2002) Changes in a California Estuary: A Profile of Elkhorn Slough. Elkhorn Slough Foundation, Moss Landing, 280 p.

[2] Van Dyke, E. and Wasson, K. (2005) Historical Ecology of a Central California Estuary: 150 Years of Habitat Change. Estuaries, 28, 173-179. http://dx.doi.org/10.1007/BF02732853

[3] Caldwell, M.R., Hartge, E.H., Ewing, L.C., Griggs, G., Kelly, R.P., Moser, S.C., Newkirk, S.G., Smyth R.A and Woodson, C.B. (2013) Chapter 9: Coastal Issues. In: Garfin, G., Jardine, A., Meredith, R., Black, M. and LeRoy, S., Eds., Assessment of Climate Change in the Southwest United States: A Report Prepared for the National Climate Assessment, Southwest Climate Alliance, Island Press, Washington DC, 168-196. http://dx.doi.org/10.5822/978-1-61091-484-0_9

[4] Cash, D.W., Clark, W.C., Alcock, F., Dickson, N.M., Eckley, N., Guston, D.H., Jager, J. and Mitchell, R.B. (2003) Knowledge Systems for Sustainable Development. Proceedings of the National Academy of Sciences of the United States of America, 100, 8086-8091. http://dx.doi.org/10.1073/pnas.1231332100

[5] Langridge, S., Hartge, E.H., Clark, R.C., Arkema, K., Verutes, G.M., et al. (2014) Key Lessons for Incorporating Natural Infrastructure into Regional Climate Adaptation Planning. Ocean \& Coastal Management, 95, 189-197. http://dx.doi.org/10.1016/j.ocecoaman.2014.03.019

[6] Hurlimann, A.C. and March, A.P. (2012) The Role of Spatial Planning in Adapting to Climate Change. Wiley Interdisciplinary Reviews: Climate Change, 3, 477-488. http://dx.doi.org/10.1002/wcc.183

[7] Wilson, E. (2006) Adapting to Climate Change at the Local Level: The Spatial Planning Response. Local Environment: The International Journal of Justice and Sustainability, 11, 609-625. http://dx.doi.org/10.1080/13549830600853635

[8] Herzog, M.M. and Hecht, S.B. (2013) Combating Sea-Level Rise in Southern California: How Local Governments Can Seize Adaptation Opportunities While Minimizing Legal Risk. Hastings West Northwest Journal of Environmental Law \& Policy, 19, 463.

[9] Downing, J., Blumberg, L. and Hallstein, E. (2014) Reducing Climate Risks with Natural Infrastructure. Report for the Nature Conservancy California, 1-28.

[10] McMahon, E. (2000) Looking Around: Green Infrastructure. Planning Commission Journal, No. 37.

[11] Caldwell, M. and Segall, C.H. (2007) No Day at the Beach: Sea Level Rise, Ecosystem Loss, and Public Access along the California Coast. Ecology Law Quarterly, 34, 533-578. 